\title{
Down-regulation of CHERP inhibits neuroblastoma cell proliferation and induces apoptosis through ER stress induction
}

\author{
Dunke Zhang ${ }^{1,2}$, Feng Wang ${ }^{1}$, Yi Pang ${ }^{1}$, Xiao-Xue $\mathrm{Ke}^{1}$, Shunqin Zhu ${ }^{1}$, Erhu Zhao ${ }^{1}$, \\ Kui Zhang ${ }^{1}$, Lixue Chen ${ }^{2}$ and Hongjuan Cui ${ }^{1}$ \\ ${ }^{1}$ State Key Laboratory of Silkworm Genome Biology, The Institute of Sericulture and Systems Biology, Southwest University, \\ Chongqing, China \\ ${ }^{2}$ Laboratory Research Center, The First Affiliated Hospital of Chongqing Medical University, Chongqing, China \\ Correspondence to: Hongjuan Cui, email: hongjuan.cui@gmail.com, hcui@swu.edu.cn \\ Keywords: CHERP, cell proliferation, colony formation, neuroblastoma \\ Abbreviations: CHERP, calcium homeostasis endoplasmic reticulum protein; ERS, ER stress; Dox, doxorubicin; mTOR, mammalian \\ target of rapamycin; $4 \mathrm{E}-\mathrm{BP}$ 1, eukaryotic initiation factor 4E-binding protein-1. \\ Received: April 18, $2017 \quad$ Accepted: August 04, $2017 \quad$ Published: September 15, 2017 \\ Copyright: Zhang et al. This is an open-access article distributed under the terms of the Creative Commons Attribution License 3.0 \\ (CC BY 3.0), which permits unrestricted use, distribution, and reproduction in any medium, provided the original author and source \\ are credited.
}

\section{ABSTRACT}

Neuroblastoma is a childhood tumor that is derived from the sympathetic nervous system. In recent years, great progress has been made in our understanding of neuroblastoma. However, applying theories to improve disease outcomes remains challenging. In this study, we observed that calcium homeostasis endoplasmic reticulum protein (CHERP) was involved in the maintenance of neuroblastoma cell proliferation and tumorigenicity. Moreover, elevated CHERP expression was positively correlated with poor patient survival, whereas low CHERP expression was predictive of better outcomes. Additional functional studies showed that CHERP knockdown inhibited neuroblastoma cell proliferation in vitro and resulted in defective tumorigenicity in vivo. Moreover, CHERP depletion suppressed neuroblastoma cell proliferation by inducing endoplasmic reticulum stress and cell apoptosis. Considering the functional roles of CHERP in neuroblastoma development and maintenance, CHERP might function as a novel therapeutic target for neuroblastoma patients.

\section{INTRODUCTION}

Neuroblastoma is a common and malignant tumor that develops from the sympathetic nervous system in children usually younger than 5 years of age $[1,2]$. Neuroblastoma symptoms may include abdominal mass, pain, diarrhea, or a general feeling of discomfort. Neuroblastoma deaths account for $12 \%$ of cancer-associated deaths among children [3]. Despite great advances in clinical treatment in recent years, the 5-year overall survival of patients with malignant neuroblastoma remains lower than $40 \%$ [4]. Understanding the exact mechanism involved in the occurrence and development of neuroblastoma will help to improve preventive measures and treatment strategies for this poorly understood cancer. Here, we show that calcium homeostasis endoplasmic reticulum protein (CHERP) is involved in neuroblastoma cell proliferation, apoptosis and tumorigenicity. CHERP was first cloned and sequenced from a human erythroleukemia (HEL) cell expression library and is responsible for intracellular $\mathrm{Ca}^{2+}$ mobilization and cell growth [5]. Ryan et al. identified that CHERP interacts with RyR1 to control $\mathrm{Ca}^{2+}$ release from the endoplasmic reticulum (ER) and is primarily localized to the sarcoplasmic reticulum of rat soleus muscle [6]. Moreover, the study showed that CHERP co-localizes with IP3 receptors throughout the cytoplasmic and perinuclear regions in Jurkat $\mathrm{T}$ lymphocytes [7]. However, recent research has shown that CHERP interacts with 17S U2 small nuclear ribonucleoproteins, partially functions as a splicing factor and is present in nuclear speckles $[8,9]$. Lin-Moshier et al. identified that CHERP is specifically located in the nucleus, including nuclear speckles [10]. Sasaki-Osugi et al. revealed that in HT1080 cells, CHERP participates in the regulation of alternative splicing of IP3R1 pre-mRNA [11]. To date, the role of CHERP in tumor biology remains unclear. 
There are two primary pathways that regulate apoptosis in mammalian cells: the intrinsic and extrinsic pathways [12, 13]. In the intrinsic pathway, DNA damage, hypoxia, and growth factor deprivation activates the Bcl-2 family members (Bax and Bak) and results in the mitochondrial release of cytochrome $\mathrm{c}$ to induce apoptosis $[14,15]$. The extrinsic pathway is activated by interaction of the tumor necrosis factor-related apoptosis-inducing ligand (TRAIL) with death receptors on the cell surface [16]. As previously reported, TRAIL-mediated apoptosis is a promising target for the clinical treatment of neuroblastoma [17-20]. Death receptor 5 (DR5) is an apoptosis-inducing receptor; once TRAIL binds to DR5, the adaptor Fas-associated DD (FADD) and pro-caspase- 8 are recruited to the bound receptor. This interaction causes self-activation of pro-caspase-8, which processes downstream effector caspases such as caspase- 3 and caspase-9 and thus leads to apoptosis [21-23]. Numerous lines of evidence have shown that ER stress (ERS) can upregulate DR5 expression, and this process plays an important role in the initiation of apoptosis of human cancer cells [24, 25]. Additionally, activation of ER stress can inhibit the AKT/mTOR signaling pathway in numerous types of tumor cells [26-28]. Mammalian target of rapamycin (mTOR) is commonly activated in multiple tumors and forms two multiprotein complexes, mTORC1 and mTORC2, that control various cellular processes, including cell proliferation, metabolism, invasion, and autophagy [29-33]. mTORC1 can phosphorylate and inactivate the translational inhibitor 4E-BP to control protein synthesis and cell cycle processes [31].

In this study, we found that depletion of CHERP could induce ER stress, leading to activation of DR5 and inhibition of the AKT/mTOR signaling pathway. Additionally, treatment with the ER stress-specific inhibitor GSK2606414 partially rescued DR5-dependent apoptosis triggered by CHERP depletion. In brief, we reveal that the down-regulation of CHERP induces apoptosis in neuroblastoma cells by activating the ATF4/ CHOP/DR5 signaling axis and inhibiting the AKT/mTOR signaling pathway. These results indicate that targeting CHERP might be a potential and novel therapeutic strategy for patients with neuroblastoma.

\section{RESULTS}

\section{High CHERP expression in neuroblastoma patients is associated with poor prognosis}

To investigate whether aberrant CHERP expression is associated with the prognosis of neuroblastoma patients, we used the Tumor Neuroblastoma public database (available from the online R2: Genomics Analysis and Visualization Platform). We selected three commonly used datasets (Versteeg, Kocak and Asgharzadeh), which contain data from 88, 476 and 247 neuroblastoma patients, respectively, to evaluate the effects of CHERP on overall patient survival. Kaplan-Meier analysis showed that high
CHERP expression was associated with poor prognosis, whereas low CHERP expression was associated with good prognosis (Figure 1A). Moreover, based on the Versteeg dataset, CHERP was expressed significantly more highly in the overall death, older age ( $>18$ month) and tumorcaused death groups than in the control group (Figure 1B). These results suggest that CHERP might be a diagnostic marker of neuroblastoma. To confirm this observation, we used data from the Neuroblastoma Prognosis Database, and the Kaplan-Meier analysis revealed that high CHERP expression was prognostic for poor outcomes in the Oberthuer Lab and Seeger dataset (Supplementary Figure 1A and 1B). Moreover, high CHERP expression significantly correlated with advancing tumor stage in the data extracted from the Kocak and Versteeg datasets (Supplementary Figure 1C). Furthermore, we analyzed whether CHERP expression levels were associated with MYCN expression in neuroblastoma patients. The results from the three datasets showed that CHERP expression increased significantly in the MYCN amplification group (Supplementary Figure 1D). In conclusion, higher CHERP expression is markedly associated with poor overall survival in neuroblastoma patients, which indicates that CHERP is a prognostic marker for neuroblastoma.

\section{CHERP is generally expressed in neuroblastoma and is located in nuclei}

To confirm the CHERP expression levels in six neuroblastoma cell lines, we performed immunoblot analysis and qRT-PCR assays and observed that CHERP was commonly expressed in neuroblastoma cell lines with $\mathrm{BE}(2)-\mathrm{C}$ cells exhibiting the highest levels and SHEP1 cells exhibiting the lowest levels (Figure 1C and 1D, respectively); thus, we chose these two cell lines for further studies. In rat soleus muscle tissue, CHERP was reported to co-localize with RyR1 in the sarcoplasmic reticulum [6]. However, recent data show that CHERP acts as a nucleoprotein and impacts cellular proliferation in HEK293 and SKBR3 cells [10]. To confirm the definitive localization of CHERP in neuroblastoma cells, we extracted nuclear and cytoplasmic proteins and used western blot assays to determine the precise location of CHERP. We found that in the neuroblastoma cell lines BE(2)-C, SK-N-DZ and SHEP1, endogenous CHERP was detected in the nucleus but not in the cytoplasm (Figure 1E). Moreover, immunofluorescence assays showed that CHERP localized to the nucleus in BE(2)-C and SHEP1 cells (Figure 1F). These observations demonstrate that CHERP is commonly expressed in neuroblastoma cells and is located in the nucleus.

\section{CHERP depletion inhibits neuroblastoma cell proliferation in vitro}

To verify the importance of CHERP in neuroblastoma, we employed a lentivirus system carrying 
small hairpin RNA (shRNA) to construct plasmids against target genes and then used these reconstructed lentiviruses
(CHERPsi-1\#, CHERPsi-2\#, and GFPsi as a control) to infect $\mathrm{BE}(2)-\mathrm{C}$ and SHEP1 cells. Immunoblot analysis
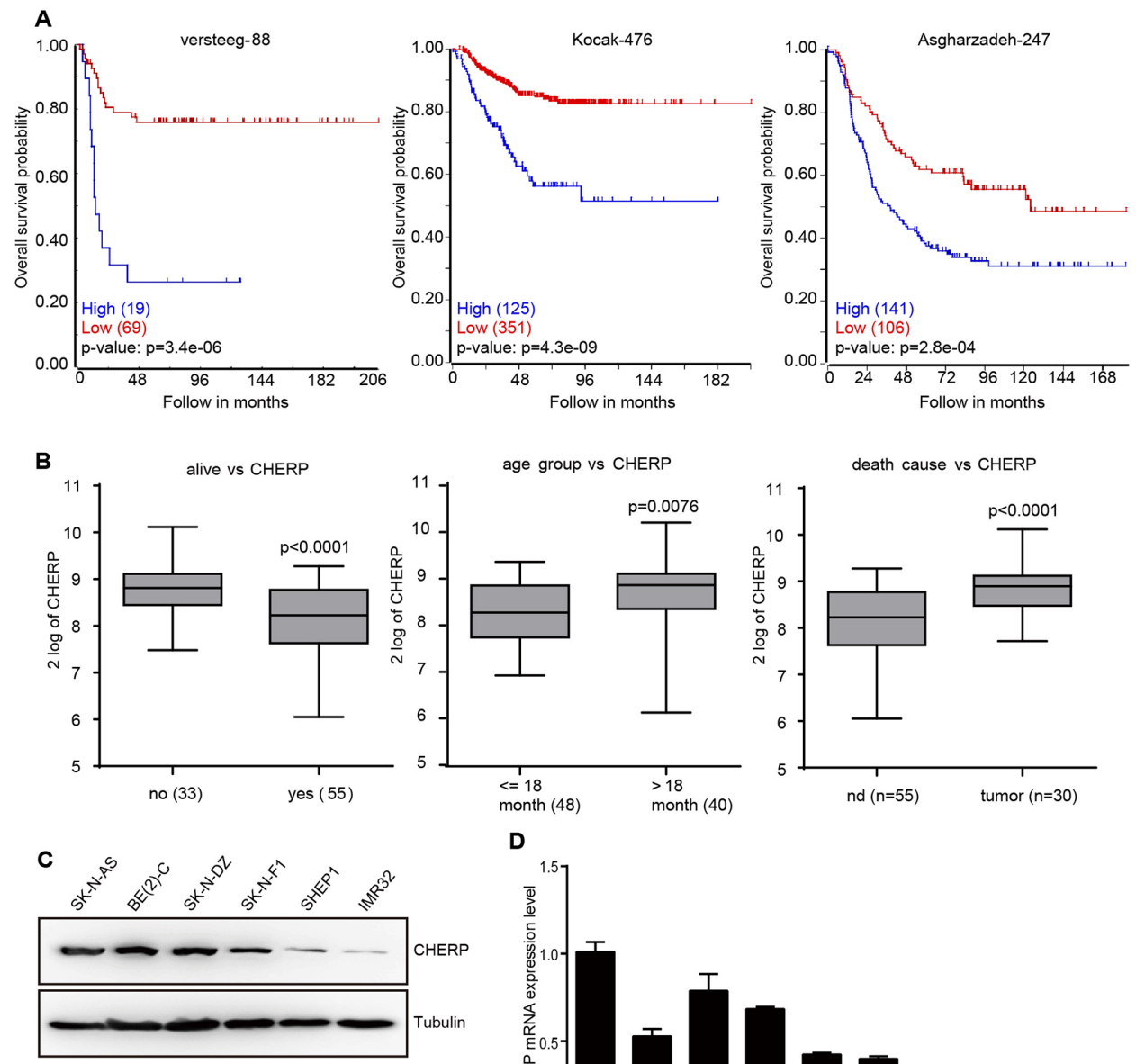

D
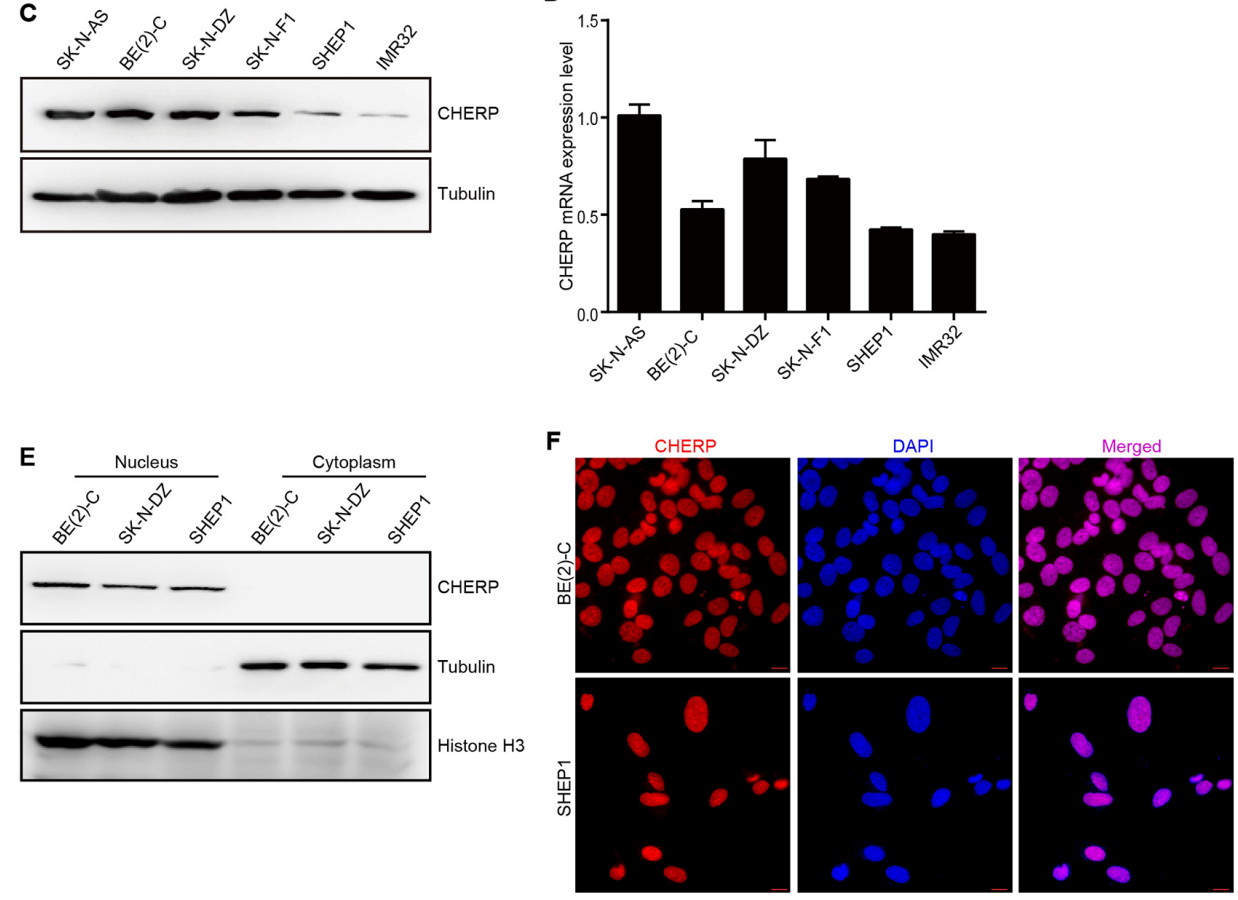

Figure 1: Elevated CHERP expression indicates a poor prognosis in neuroblastoma. High CHERP expression is associated with poor outcomes in neuroblastoma patients. (A) Overall survival curve analysis of progression-free survival of the Neuroblastoma Prognosis Database for the Versteeg, Kocak and Asgharzadeh datasets; the P-values are indicated. (B) Box plot of CHERP expression levels in tumors from the dead and living groups, groups older than or younger than 18-months-old and the cause-of-death groups; the P-values are indicated. CHERP expression levels analyzed by western blotting (C) and qRT-PCR (D) in six neuroblastoma cell lines. (E) To analyze the localization of CHERP in BE(2)-C, SK-N-DZ and SHEP1 cells, nuclear and cytoplasmic extracts were prepared for western blotting. Tubulin and $\mathrm{H} 3$ histone were used as positive controls for nuclear and cytoplasmic proteins, respectively. (F) Immunostaining for CHERP (red) in BE(2)-C and SHEP1 cells; nuclei were stained with DAPI (blue). Scale bar for all microscopy images, $10 \mu \mathrm{m}$. 
and qRT-PCR assays showed that infecting cells with lentiviruses expressing targeted shRNAs resulted in significant CHERP down-regulation (Figure 2A and 2B), $* * \mathrm{P}<0.001$. Cell number was dramatically lower in the CHERPsi group than in the control group (Figure $2 \mathrm{C}$ and 2D), $* * \mathrm{P}<0.001$. This result was further supported by a growth curve assay, which revealed significant growth inhibition of cells subjected to CHERP down-regulation (Figure 2E). These data demonstrate that CHERP plays an indispensable role in neuroblastoma cell proliferation.

\section{CHERP depletion induces cell cycle arrest at G0/ G1 phase in BE(2)-C and SHEP1 cells}

The abovementioned data show that CHERP depletion inhibits neuroblastoma cell proliferation, and as reported, cell proliferation is often associated with cell cycle progression. Thus, we used flow cytometric analysis to further analyze the cell cycle status in BE(2)-C and SHEP1 cells with or without CHERP knockdown. Because both shRNAs (CHERPsi-1\# and CHERPsi-2\#) induced significant down-regulation of CHERP (Figure $2 \mathrm{~A}$ and $2 \mathrm{~B}$ ), we used the CHERPsi-2\# shRNA-expressing lentivirus for subsequent experiments. As shown in Figure $3 \mathrm{~A}$, cell cycle analysis of CHERP-depleted cells indicated a significant increase in the proportion of cells in the $\mathrm{G} 0$ / $\mathrm{G} 1$ phase concomitant with a significant reduction in $\mathrm{S}$ phase compared with the corresponding proportions in the GFPsi cell population. These data showed that CHERP depletion induced cell cycle arrest at G0/G1 phase in BE(2)-C and SHEP1 cells, $* * P<0.001$. Furthermore, we stained cells for the proliferation marker Ki67 and observed that the $\mathrm{Ki67}$-positive cell population was significantly decreased in CHERP-depleted cells relative to that in the control cells (Figure $3 \mathrm{~B}$ ), $* * \mathrm{P}<0.001$. To validate these results, we evaluated G1/S checkpointassociated proteins using western blot analysis. The expression levels of CDK2 and Cyclin E were decreased in CHERP-depleted cells, but there were no obvious changes in the expression levels of CDK1, CDK4 or Cyclin B1 (Figure 3C). These results suggest that CHERP represses neuroblastoma cell proliferation by reducing CDK2 and Cyclin E expression and inducing cell cycle arrest at G0/ G1 phase.

\section{CHERP depletion induces cell apoptosis in BE(2)-C and SHEP1 cells}

Because apoptosis may reduce cell proliferation and inhibit tumor growth, we detected nuclear condensation in CHERP-depleted cells using Hoechst 33258 staining. The nuclei of cells in the GFPsi group were large and round with a smooth nuclear membrane, whereas the nuclei in the CHERPsi group exhibited fragmentation, which indicated that CHERP depletion induced apoptosis and affected nuclear morphology (Figure 4A). As shown on the right, the quantitative analysis of cells with fragmented nuclei demonstrated that the proportion of cells with fragmented nuclei (\%) in the CHERPsi group was dramatically higher than that in the GFPsi group, $* \mathrm{P}<0.05$. Furthermore, flow cytometry analysis of annexin-V-FITC and PI staining confirmed that the cell apoptosis rate was notably increased in the CHERPdepletion group (Figure 4B). Quantitative analyses of Figure 4B are shown on the right and illustrate that the cell apoptosis rate was dramatically increased by up to $52.2 \%$ in CHERPsi BE(2)-C cells and up to $76.3 \%$ in CHERPsi SHEP1 cells. Next, we analyzed the expression levels of several apoptosis-associated proteins using western blot analysis. Cleaved caspase- 3 and cleaved caspase- 8 were up-regulated in CHERP depletion cells compared with the levels in the GFPsi cells (Figure 4C). These results demonstrated that down-regulating CHERP could induce neuroblastoma cell apoptosis in vitro.

\section{CHERP depletion results in alterations in the drug sensitivity and cell viability of neuroblastoma cells in response to Dox}

One of the important properties of cancer cells is their resistance to drugs. Therefore, we investigated whether depleting CHERP could affect the response of neuroblastoma to doxorubicin (Dox) treatment. We treated CHERP-depleted cells with $2 \mu \mathrm{M}$ Dox for the indicated time. The clonogenic assays revealed that compared with the GFPsi group, the BE(2)-C (Figure 5A) and SHEP1 (Figure 5B) CHERPsi groups exhibited impaired Dox resistance in a time-dependent manner. The right panel is the quantitative analysis of the crystal violet staining after elution with $33 \%$ acetic acid and measurement at $\mathrm{OD}_{600}$. In addition, we treated CHERP-depleted cells with $2 \mu \mathrm{M}$ Dox and extracted total protein for western blot assays. Consistent with the results from the clonogenic assays, the cleaved caspase- 3 and cleaved caspase- 8 protein levels showed dramatic increases compared with the levels in the control group (Figure 5C). These results showed that down-regulating CHERP could attenuate the drug sensitivity to Dox and cell viability of neuroblastoma cells.

\section{CHERP depletion inactivates mTOR and induces apoptosis in neuroblastoma cells by CHOP-dependent DR5 induction}

Thus far, we have shown that CHERP depletion can induce neuroblastoma cell apoptosis and increase the expression of cleaved caspase- 3 and cleaved caspase- 8 expression. Although most human neuroblastoma cells exhibit drug resistance because of their low levels of caspase- 8 expression, previous reports have shown that TRAIL-receptor 2 (TRAIL-R2/DR5/TNFRSF10b) is an important upstream effector of caspase-8 [34]. Thus, we then examined the DR5 levels in CHERP-depleted cells. 
Consistent with our expectations, DR5 was significantly up-regulated at both the mRNA and protein levels (Figure 6A and 6B). As previously reported, ER stress in response to CHOP can induce DR5 transcription $n$ human carcinoma cells [35]. To determine whether DR5 transcription is regulated by ER stress in neuroblastoma cells, we examined the ER stress marker proteins BIP,

A

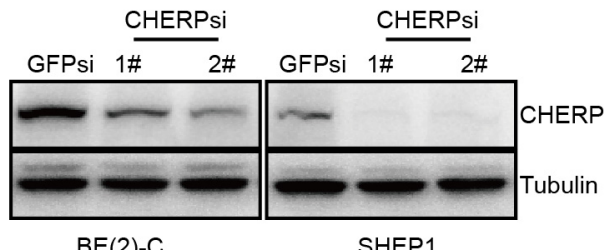

C

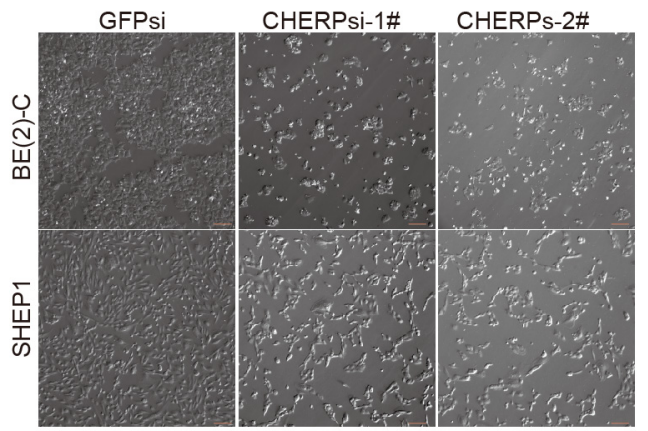

\section{E}

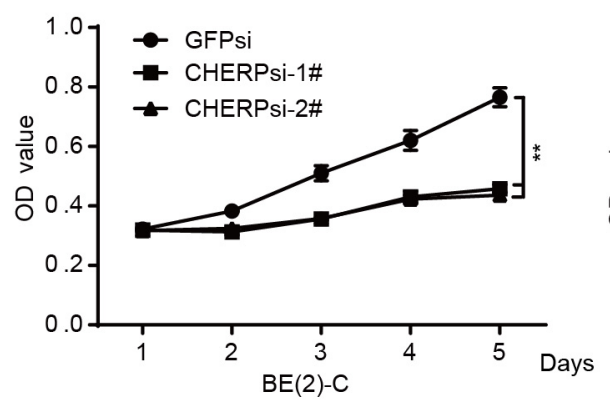

ATF4 and CHOP. Depletion of CHERP in BE(2)-C and SHEP1 cells dramatically increased BIP, ATF4 and CHOP expression, which suggested that ER stress was involved in neuroblastoma cell apoptosis induced by CHERP depletion. To confirm this observation, we treated cells with the ER stress inhibitor GSK2606414 [36, 37]. The addition of $50 \mu \mathrm{g}$ of GSK2606414 resulted in a reduction
D

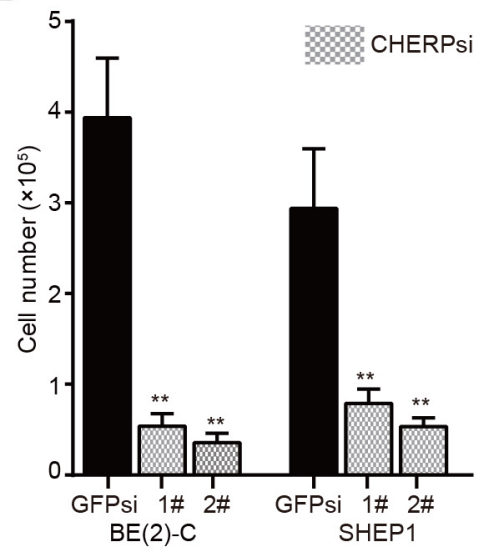

B

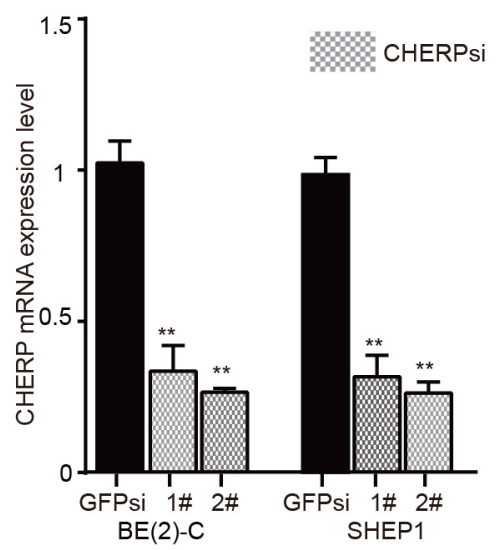
$\operatorname{BE}(2)-C \quad$ SHEP1 $\mathrm{BE}(2)-\mathrm{C}$

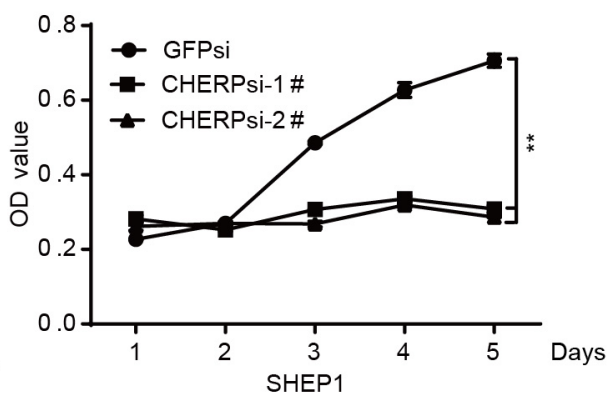

Figure 2: CHERP depletion decreases cell viability by inhibiting proliferation in vitro. BE(2)-C and $\mathrm{SHEP} 1$ cells were transfected with CHERPsi-1\# or CHERPsi-2\# sequences with GFPsi as a biological control. The efficiency of shRNA-mediated interference was detected using western blotting (A) and qRT-PCR (B) in BE(2)-C and SHEP1 cells. (C) The number of cells decreased in CHERPsi-1\# and CHERPsi-2\# groups relative to that in the GFPsi group. Scale bar for all microscopy images, $100 \mu \mathrm{m}$. (D) BE(2)-C and SHEP1 cells expressing GFPsi, CHERPsi-1\# or CHERPsi-2\# were analyzed for cell counting $72 \mathrm{~h}$ after transfection. (E) CCK8 proliferation assays of BE(2)-C and SHEP1 cells expressing GFPsi, CHERPsi-1\# or CHERPsi-2\#. All data were analyzed using Student's t-test; *p < 0.05, **p $<0.001$. 
A
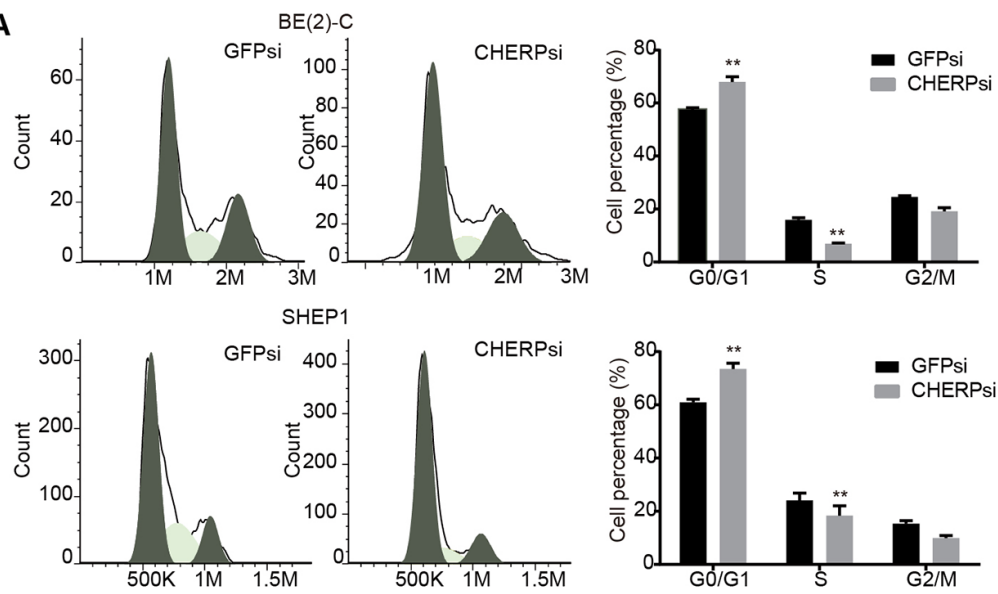

B

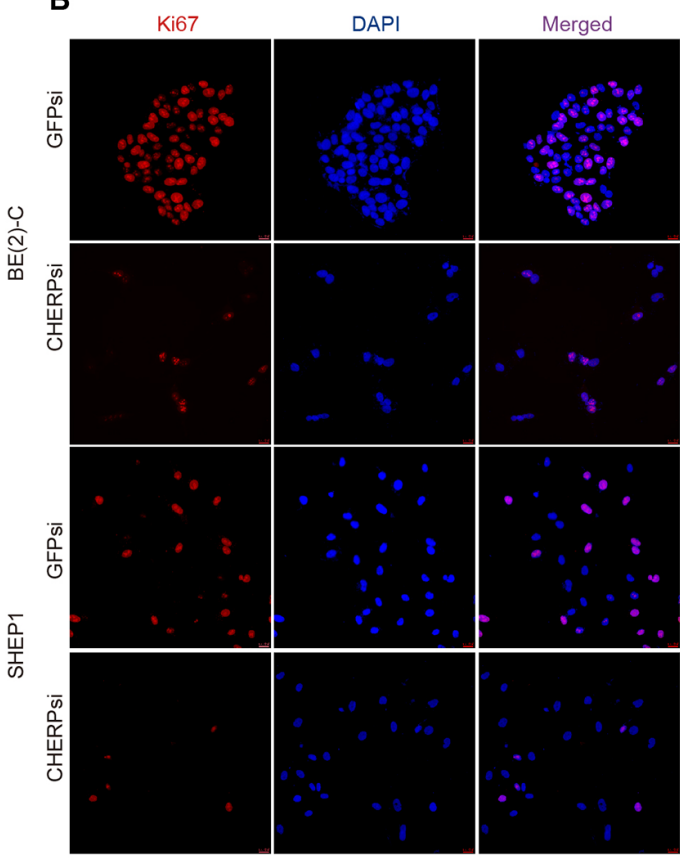

C

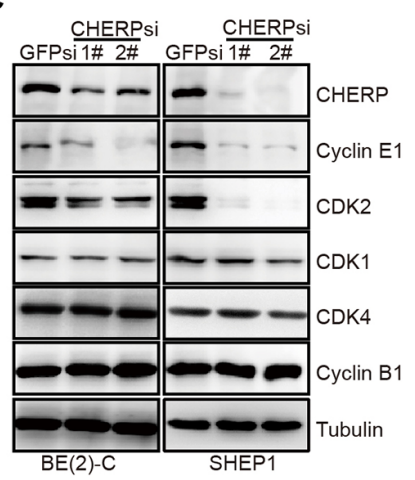

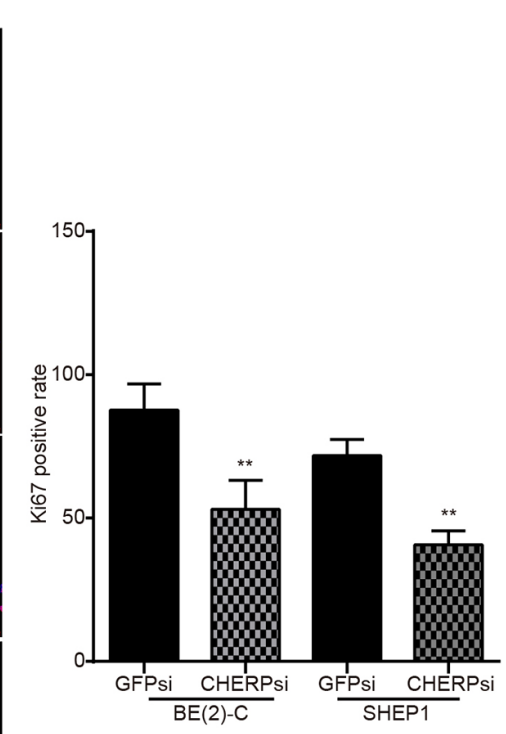

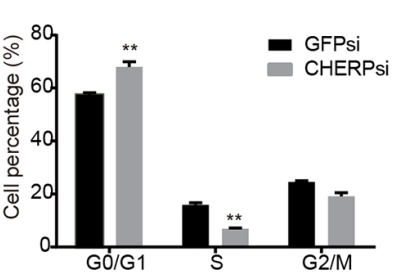

Figure 3: CHERP depletion induces cell cycle arrest in vitro. CHERP depletion significantly increased the proportion of the cell population at G1 phase and decreased the proportion of cells in S phase in neuroblastoma. (A) Cell cycle analysis of BE(2)-C and SHEP1 cells using flow cytometry. (B) Ki67 staining analysis with Ki67 (red) and DAPI (blue). Quantification of Ki67-positive cells is presented on the right; all data were measured at least three times and were obtained from three independent images. Values are shown as the mean \pm $\mathrm{SD}, * * \mathrm{p}<0.001$. (C) Expression of cyclins and CDKs associated with G1 phase as detected using western blotting. 

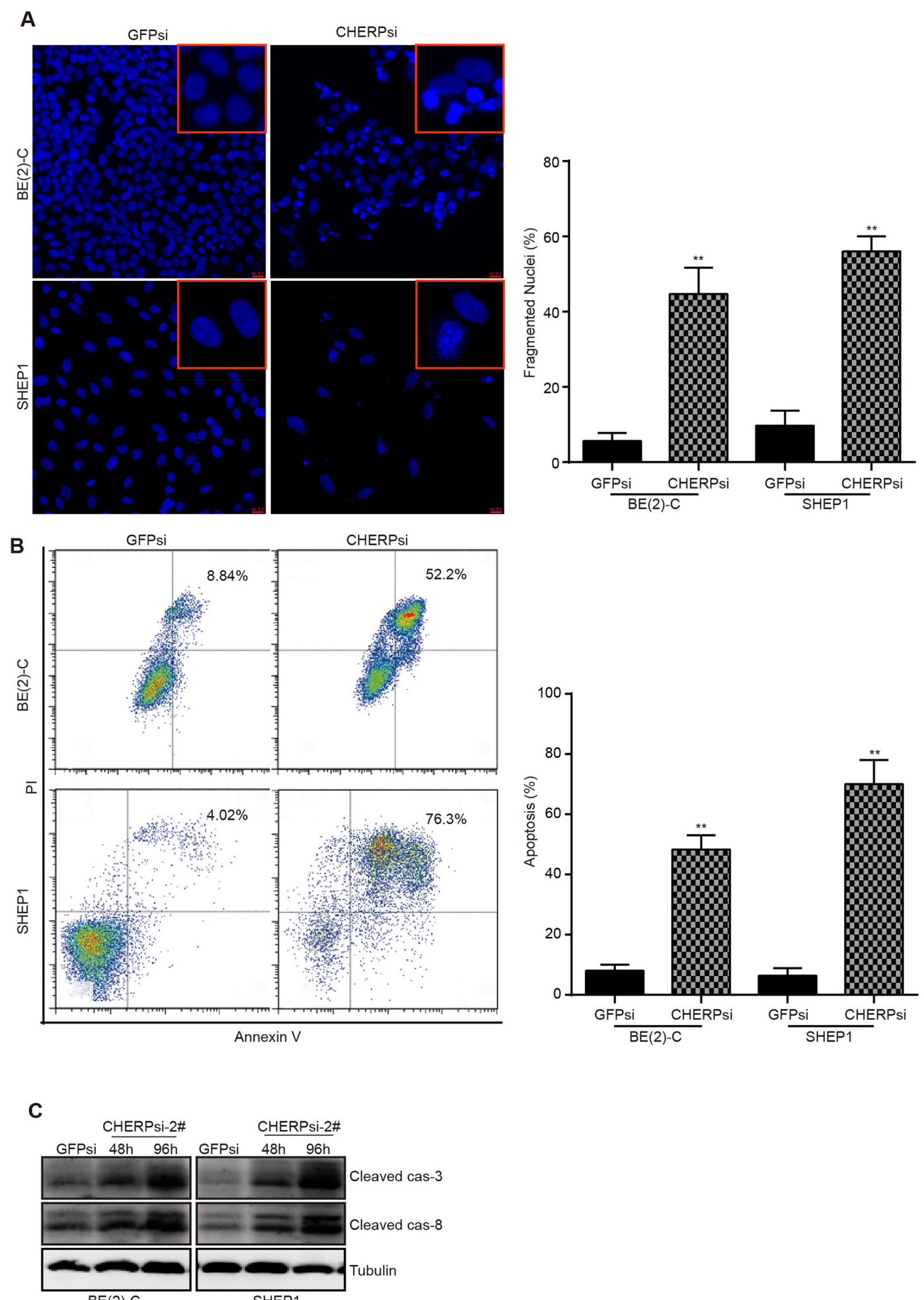

$\mathrm{BE}(2)-\mathrm{C}$

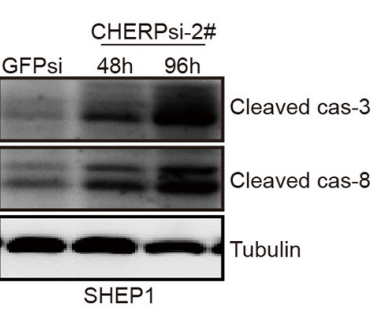

Figure 4: CHERP depletion induces neuroblastoma cells apoptosis. (A) Hoechst 33258 staining for BE(2)-C and SHEP1 cells; regions of cells are magnified in the red frames. Scale bar for all microscopy images, $10 \mu \mathrm{m}$. Quantification of Hoechst 33258-stained cells is shown on the right; all data were measured at least three times and were obtained from three independent images. (B) Apoptosis analysis of BE(2)-C and SHEP1 cells using flow cytometry. Quantification of apoptotic cells is presented on the right, and all data were analyzed using Student's t-test, ${ }^{*} \mathrm{P}<0.001$. (C) Expression of apoptosis-associated proteins (cleaved caspase-3 and cleaved caspase-8) as detected using western blotting. 

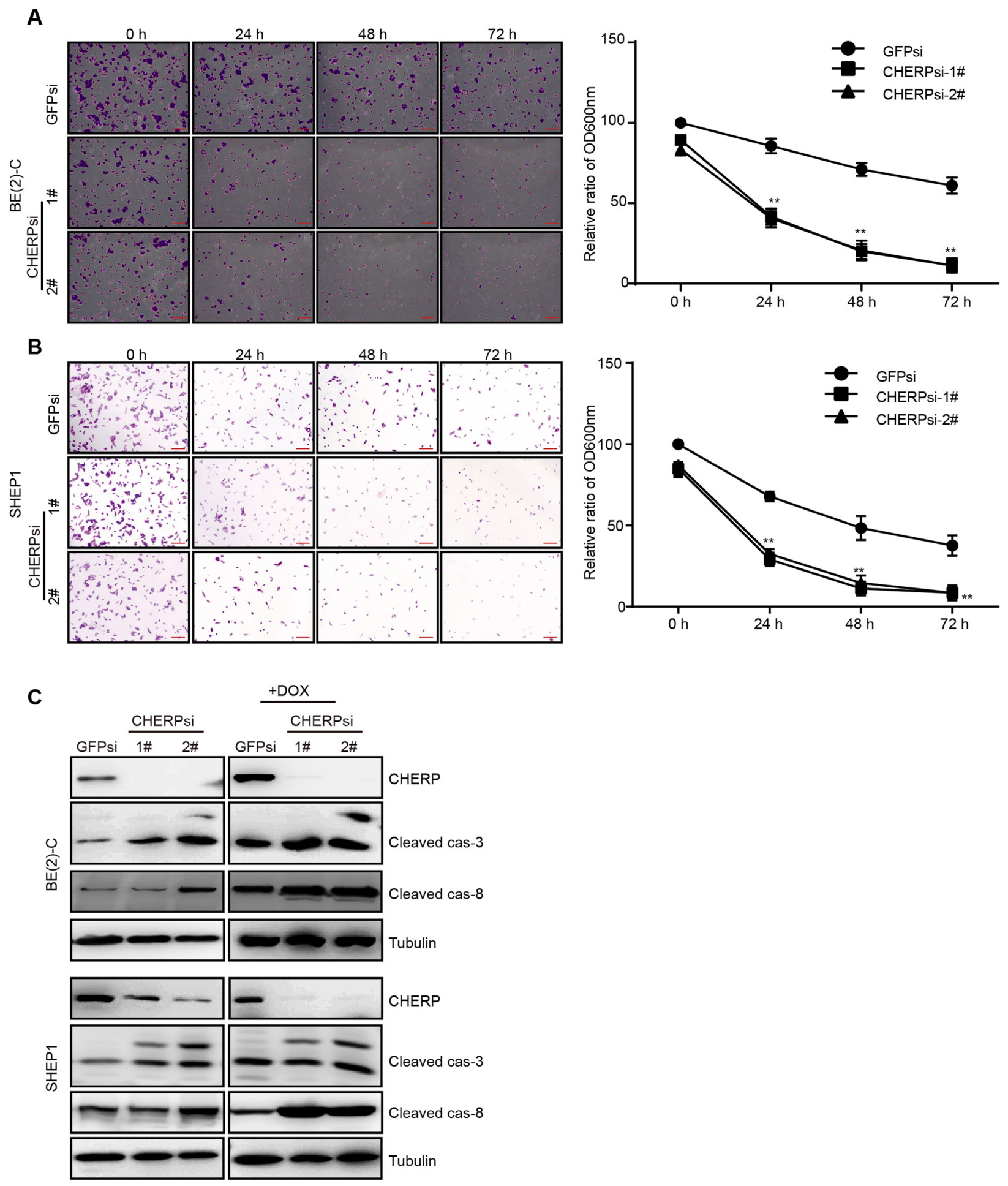

Figure 5: CHERP depletion results in alterations in the sensitivity of neuroblastoma cells to DOX. Clonogenic assays of BE(2)-C (A) and SHEP1 (B) cells expressing GFPsi, CHERPsi-1\# or CHERPsi-2\# sequences and treated with $2 \mu \mathrm{M}$ Dox for the indicated time $(0 \mathrm{~h}, 24 \mathrm{~h}, 48 \mathrm{~h}$ or $72 \mathrm{~h})$; colonies were stained with crystal violet solution and quantified. Scale bar for all microscopy images, 100 $\mu \mathrm{m}$. Quantification of the stained colonies is shown in the right panel. All data are shown as the mean $\pm \mathrm{SD},{ }^{* * \mathrm{P}} \leq 0.001$. All $\mathrm{p}$-values are based on analysis of control versus treatment. (C) Western blot analysis was performed to determine the expression of apoptosis-associated proteins (cleaved caspase-3 and cleaved caspase-8). 

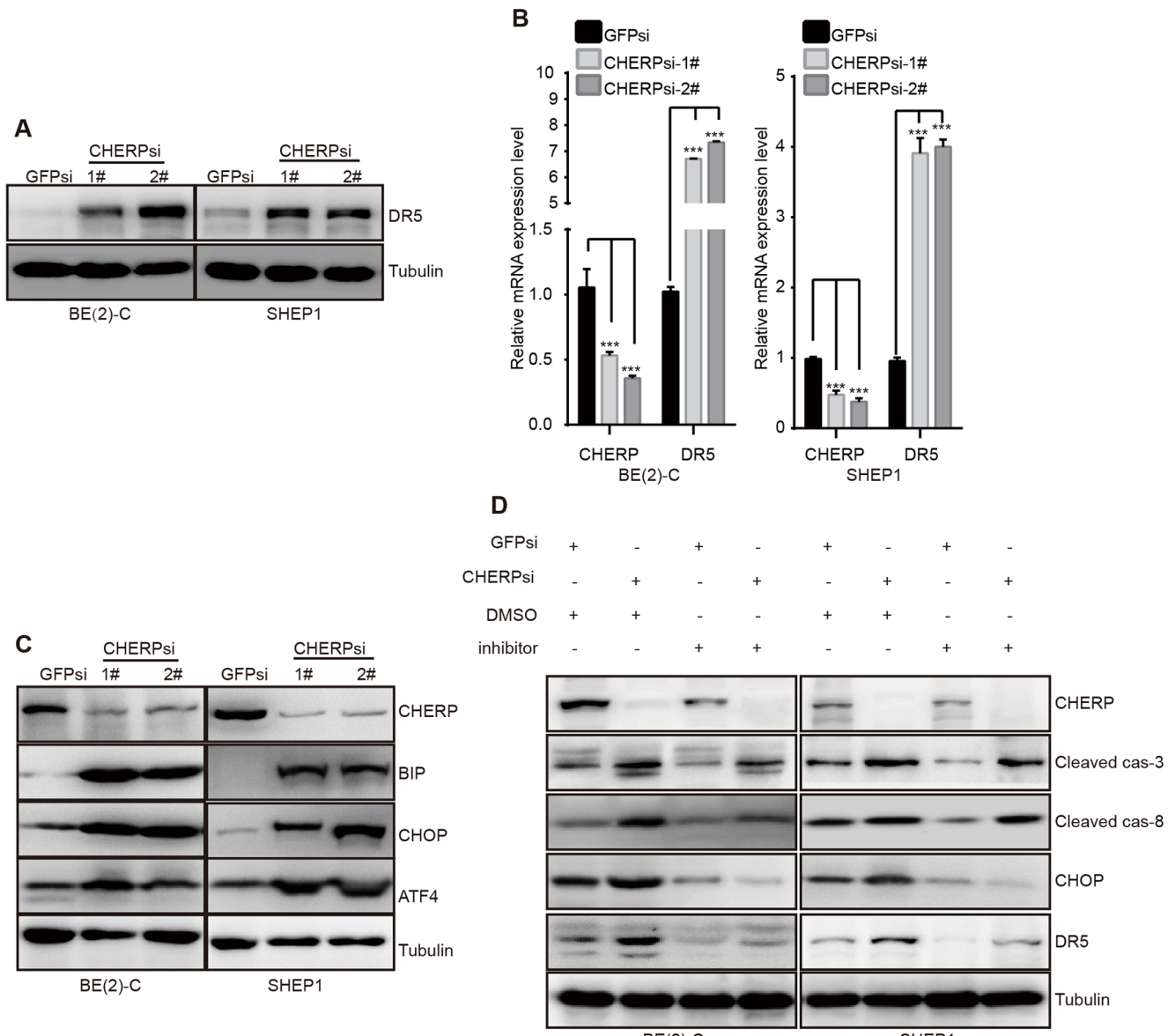

$E$

F
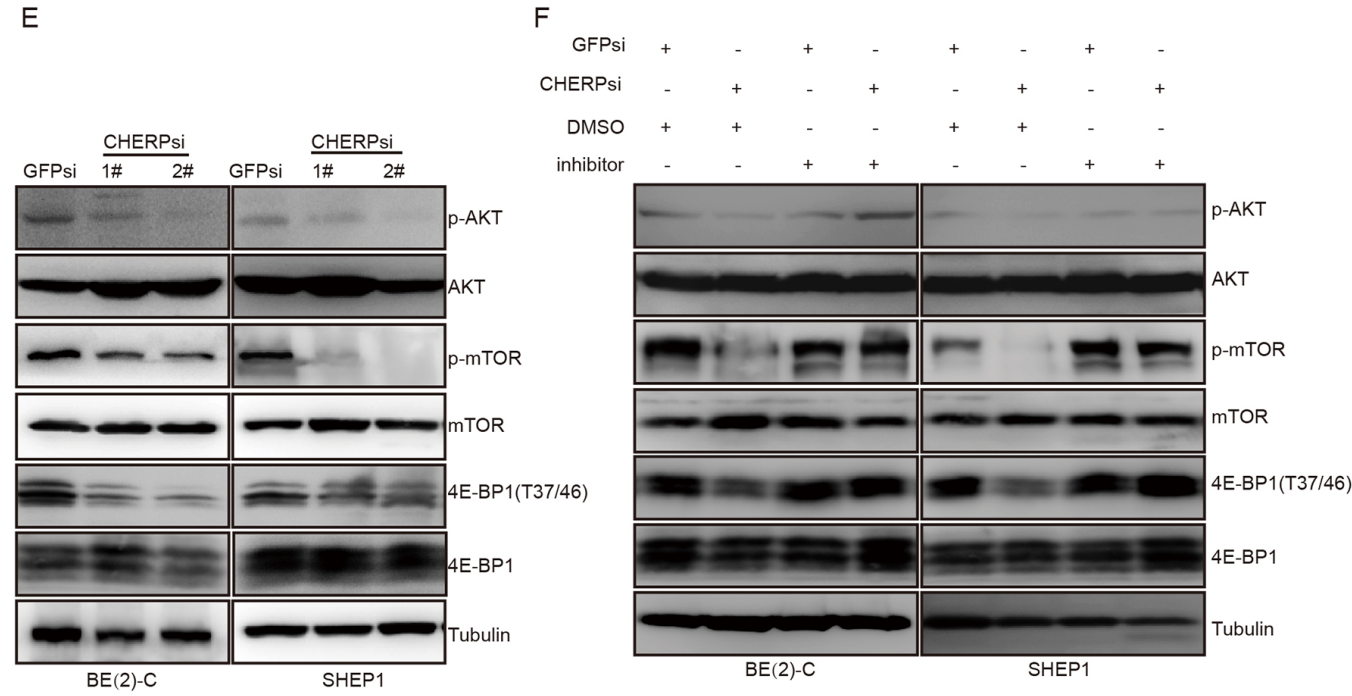

Figure 6: CHERP depletion induces neuroblastoma cell apoptosis via the ER stress pathway. ER stress and AKT/mTOR signaling are involved in the induction of CHERP depletion-mediated neuroblastoma cell apoptosis. (A) Western blot analysis was performed to measure DR5 protein expression. (B) DR5 mRNA levels as evaluated by qRT-PCR; the values represent the mean \pm S.D. (n $=3$ ). All data were analyzed by Student's t-test, $* * P<0.001$. (C) ER stress-associated proteins as analyzed by western blotting. BE(2)-C and SHEP1 cells expressing GFPsi, CHERPsi-1\# or CHERPsi-2\# sequences were treated with $50 \mu \mathrm{g}$ of the ERS inhibitor GSK2606414, and the indicated proteins were detected using western blotting (D). AKT, mTOR and 4E-BP1 expression levels were also analyzed using western blotting (E and F). 
in the cleaved caspase- 3 and cleaved caspase- 8 expression levels to those observed in the GSK2606414-negative group. CHOP and DR5 expression also decreased in CHERP-depleted BE(2)-C and SHEP1 cells treated with GSK2606414 (Figure 6D). As previously reported, the activation of ERS promoted apoptosis and reversed chemoresistance in human small cell lung cancer (SCLC) cells by inhibiting the PI3K/AKT/mTOR pathway [26]. As shown in Figure 6E, we found that the levels of AKT, mTOR and 4E-BP1 phosphorylation were attenuated after CHERP depletion, which indicated that the AKT/ mTOR/4E-BP1 pathway was involved in neuroblastoma cell apoptosis mediated by CHERP depletion. Furthermore, after GSK2606414 treatment, we found that AKT, mTOR and 4E-BP1 phosphorylation were rescued; these results suggested that CHERP depletion could inhibit the AKT/mTOR/4E-BP1 pathway via activation of ERS (Figure 6F). In conclusion, these results indicate that ER stress is involved in neuroblastoma cell apoptosis induced by CHERP depletion; moreover, up-regulation of DR5 and inhibition of the AKT/mTOR/4E-BP1 pathway represent two separate downstream events of this process.

\section{CHERP depletion reduces neuroblastoma cell colony formation and represses tumorigenicity in vitro and in vivo}

To investigate whether CHERP depletion could affect tumorigenicity in neuroblastoma cells, we performed a soft-agar colony-formation assay. The size and number of colonies were obviously reduced in CHERP-depleted cells, $* * \mathrm{P}<0.001$ (Figure 7A and 7B). Furthermore, we investigated the role of CHERP in the tumorigenicity of neuroblastoma cells in vivo by subcutaneously implanting CHERP-depleted BE(2)-C cells into immunodeficient mice. In the animal model images, red arrows and dashed lines indicate the positions of the xenograft tumors. CHERP depletion impaired tumor growth compared with that in the GFPsi group, and mice injected with CHERPsi-2\# cells did not form xenograft tumors $* * \mathrm{P}<$ 0.001 (Figure 7C-7E). Taken together, these experiments indicate that CHERP plays a key role in the colonyforming ability and tumorigenicity of neuroblastoma. Figure 7F presents a diagram of the mechanism by which CHERP regulates neuroblastoma cell proliferation and apoptosis. In brief, CHERP depletion induces ER stress and CHOP-dependent DR5 transcription, attenuates mTOR and 4EBP1 phosphorylation, and ultimately induces neuroblastoma cell apoptosis.

\section{DISCUSSION}

Although some studies performed in mammalian cells have elucidated some functions of CHERP, such as controlling intracellular $\mathrm{Ca}^{2+}$ mobilization and cell growth, acting as part of splicing factors and participating in post- transcriptional regulation of splicing variants in $\mathrm{Ca}(2+)$ signaling pathways, etc. $[5,10,11]$, there has been little progress in understanding the role of CHERP in humans, especially in human cancer cells. Here, we determined that CHERP expression was a potential prognostic marker in neuroblastoma patients. High CHERP expression was associated with poor outcomes, and low expression was associated with a good prognosis. Moreover, CHERP expression was associated with patient age, cause of death and stages and MYCN status of neuroblastoma patients. O'Rourke et al. cloned CHERP and found that this protein is localized to the ER $[5,7]$. Ryan et al. showed that CHERP interacts with RyR1 in the sarcoplasmic reticulum of rat soleus muscle [6]. Lin-Moshier et al. and SasakiOsugi et al. found that CHERP acts as a nuclear protein $[10,11]$. To date, the definitive cellular location of CHERP has not been established, which may indicate multiple functions of CHERP in different cells or locations. Here, we verified that CHERP is located in the nuclei in neuroblastoma cells and revealed its role in controlling cell proliferation and apoptosis during neuroblastoma initiation and development. Moreover, CHERP depletion combined with Dox treatment confirmed that CHERP plays an important role in the survival and drug resistance of neuroblastoma cells. Advances in genetics have resulted in remarkable progress in neuroblastoma treatment over the years. Our discovery of the functions of CHERP in neuroblastoma cell proliferation, apoptosis and tumorigenicity combined with integrated drug treatments may provide a new potential strategy for clinical treatment of neuroblastoma.

Further mechanistic studies revealed that CHERP depletion induces ERS and CHOP-dependent DR5 transcription; attenuates AKT, mTOR and 4EBP1 phosphorylation; and ultimately promotes neuroblastoma cell apoptosis. Emerging evidence indicates that targeting CHOP/DR5 mediates apoptosis in cancer. mTOR has been well established as a master regulator of cell growth, motility, survival, protein synthesis, and transcription. Over-activation of mTOR leads to considerable accumulation of unfolded protein in the ER and triggers ERS $[38,39]$. In addition, activation of ERS can inhibit the AKT/mTOR signaling pathway and promote cell autophagy and apoptosis in numerous tumors [40-42]. Our findings reveal that CHERP depletion can induce ERS, although the precise mechanism of this process requires further exploration.

Furthermore, our in vitro and in vivo experimental results demonstrate that the status of CHERP is essential for clone forming ability and tumorigenicity of neuroblastoma cells. Neuroblastoma cells with depleted CHERP minimally form xenotransplanted tumors in nude mice. We speculated that CHERP depletion leads to ERS and inhibits neuroblastoma initiation and that tumor progression is related to the subcellular localization of CHERP in cells. Our results validated 
previous reports that CHERP is located in the nucleus and regulates the function of the U2 snRNA spliceosomal complex [43]; therefore, we speculated that depletion of CHERP leads to U2 snRNA spliceosomal complex

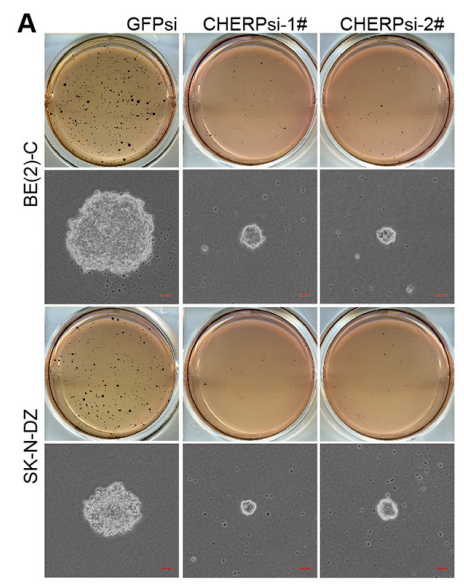

B

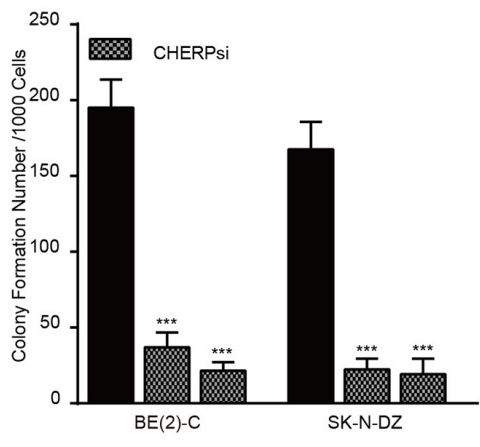

C

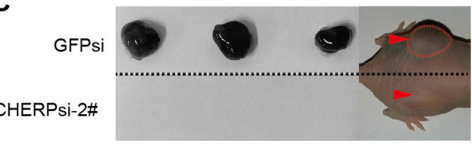

D
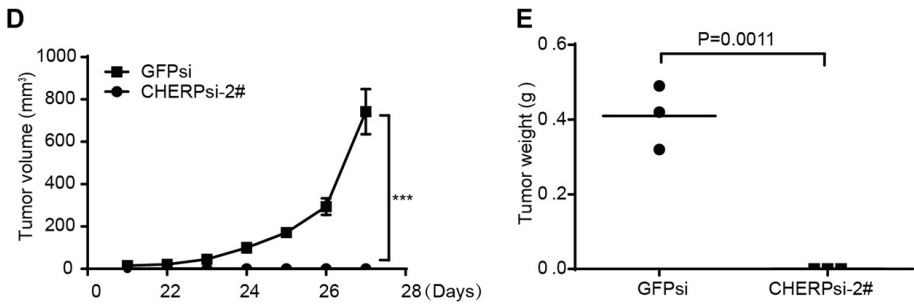

$\mathbf{F}$

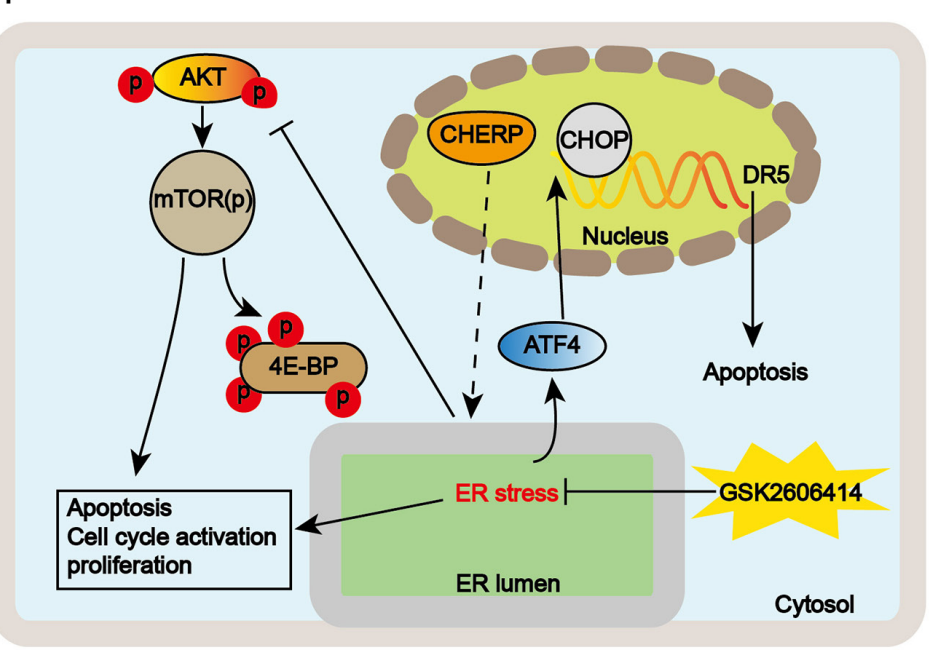

Figure 7: CHERP depletion impairs colony growth and tumorigenicity of neuroblastoma cell lines in vitro and in vivo. (A) Soft agar colony-formation assays with BE(2)-C and SK-N-DZ cells expressing GFPsi, CHERPsi-1\# or CHERPsi-2\# sequences. Colonies were stained with MTT and scored, and the quantification of the stained colonies is shown in (B). Scale bars in all microscopy images, $50 \mu \mathrm{m}$. (C) Representative tumors from the GFPsi and CHERPsi-2\# groups. Mice were imaged for 1 week after the tumors became palpable. (D) Tumor growth curve of the GFPsi and CHERPsi-2\# cells injected into immunodeficient mice. (E) The weights of the xenograft tumors formed by the GFPsi and CHERPsi-2\# BE(2)-C cells are indicated along with their p-values. All values represent the mean \pm S.D. $(n=3)$. Student's two-tailed t-test, $* * \mathrm{P}<0.001$. (F) Diagram of the mechanism by which CHERP regulates neuroblastoma cell proliferation and apoptosis. 
dysfunction and subsequently triggers ERS, interferes with cell proliferation, induces cell apoptosis and inhibits tumorigenicity. These results suggest that CHERP plays a crucial role in tumor formation and development, and this role should be studied further to fully explain the function of CHERP in neuroblastoma initiation and progression.

In summary, our study identifies CHERP as a potential target for the treatment of neuroblastoma and reveals the following novel findings: (a) CHERP is generally expressed in neuroblastoma, and high CHERP expression is associated with poor prognosis in neuroblastoma patients; (b) CHERP depletion inhibits neuroblastoma cell proliferation and induces cell cycle arrest at G0/G1 phase; (c) CHERP depletion triggers ERS and induces cell apoptosis via CHOP-dependent DR5 induction and inhibition of the AKT/mTOR signaling pathway in neuroblastoma cells; and (d) CHERP depletion impairs the clone-forming ability and tumorigenicity of neuroblastoma cells. Overall, our findings provide new insights into the mechanism whereby CHERP regulates neuroblastoma cell fate and provides a potential therapeutic target for neuroblastoma.

\section{MATERIALS AND METHODS}

\section{Cells and cell culture}

The human neuroblastoma cell lines BE(2)-C, SKN-DZ, SK-N-F1, SHEP1 and IMR32 were purchased from ATCC (Rockville, MD, USA), and all cell lines except $\mathrm{BE}(2)-\mathrm{C}$ were cultured in complete medium containing DMEM (Life Technologies, Grand Island, NY, USA) supplemented with 10\% fetal bovine serum (Invitrogen) and $1 \%$ penicillin/streptomycin (Life Technologies, Grand Island, NY, USA). BE(2)-C cells were cultured in DMEM/F-12 complete medium. All cells were maintained at $37^{\circ} \mathrm{C}$ in a humidified incubator containing $5 \% \mathrm{CO}_{2}$.

\section{Drug treatment}

Doxorubicin (Dox) was purchased from Abcam (ab120629) and dissolved in double-distilled water. Cells infected with targeted lentiviruses for $48 \mathrm{~h}$ were grown in the presence or absence of $2 \mu \mathrm{M}$ Dox for $24 \mathrm{~h}, 48 \mathrm{~h}$ and $72 \mathrm{~h}$. At the indicated times, cells were stained with crystal violet. The stained cells were routinely examined using an inverted microscope, and the absorbance was measured at a wavelength of $600 \mathrm{~nm}$. Cells treated with $2 \mu \mathrm{M}$ Dox at $48 \mathrm{~h}$ were collected for further western blot analysis. For the GSK2606414 (Selleckchem, S7307) treatment assay, cells were cultured in the presence or absence of $50 \mu \mathrm{g}$ GSK2606414 for $2 \mathrm{~h}$, after which they were infected with targeted lentiviruses for $48 \mathrm{~h}$. Cells were collected for further western blot analysis.

\section{Transfection and viral infection}

The pLKO.1 vector was combined with $0.5 \mu \mathrm{g}$ of pLP1, pLP2 and pLP/VSVG plasmids and transfected into
293FT cells with Lipofectamine 2000 transfection agent, and the cells were cultured for $48 \mathrm{~h}$. The supernatant was collected and filtered through a $0.45-\mu \mathrm{m}$ filter. These virus-containing supernatants were used to infect target cells for $24 \mathrm{~h}$, and the remaining lentiviruses were stored at $-80^{\circ} \mathrm{C}$. After two rounds of infection, the infected cells were cultured with $2 \mathrm{mg} / \mathrm{ml}$ puromycin for one day to establish a stable cell line.

\section{Cell growth assay}

The cell growth curve was produced using a CCK8 (Beyotime) assay. After cells were infected, they were seeded into 96-well plates at 800 cells per well and cultured overnight. Then, $10 \mu \mathrm{l}$ of CCK- 8 was added to each well and incubated at $37^{\circ} \mathrm{C}$ for $2 \mathrm{~h}$, and the absorbance was measured at a wavelength of $450 \mathrm{~nm}$.

\section{Patient data analysis}

Patient data were analyzed as previously described. Briefly, the overall patient survival plots and gene expression datasets were analyzed using the R2: Microarray Analysis and Visualization Platform (http://hgserver1.amc.nl/cgi-bin/r2/main.cgi) and the Oncogenomics Section Data Center (http://pob.abcc. ncifcrf.gov/cgi-bin/JK) [44]. The survival curves and P-values (log-rank test) were downloaded online, and the gene expression data were obtained from datasets and analyzed using GraphPad Prism (version 6.0). All cutoff values for separating the high- and low-expression groups were determined using either the online R2 or Oncogenomics database algorithms [45].

\section{Western blot analysis}

Cells were lysed in RIPA Lysis Buffer (Beyotime) and mixed with PMSF (Beyotime), and protein concentrations of the resulting lysates were quantified using a BCA Protein Assay Kit (Beyotime). A total of 30 $\mu \mathrm{g}$ of protein from each sample was separated using SDSPAGE on a $10 \%$ gel and transferred to a polyvinylidene fluoride membrane. The membranes were probed with the following antibodies: 1:1000 rabbit polyclonal antiCHERP antibody (ab15951, Abcam); 1:1000 rabbit polyclonal anti-cleaved caspase-3 antibody (AC033, Beyotime); mTOR substrate antibodies (9862, CST); 1:800 polyclonal anti-DR5/TNFRSF10B antibody (BS60081, Bioworld); 1:1000 polyclonal anti-Bip antibody (3177, CST); 1:1000 CHOP polyclonal antibody (2895, CST); 1:500 AKT polyclonal antibody (4691, CST); 1:1000 polyclonal anti-P-Akt (Ser473) antibody (4060, CST); 1:800 polyclonal anti-cleaved caspase- 8 antibody (E1A5267, EnoGene); and 1:800 polyclonal anti-ATF4 antibody (E2A6008, EnoGene). For the cell cycle protein assay, either a cell cycle regulation antibody sampler kit $(9932, \mathrm{CST})$ or a 1:2000 $\alpha$-tubulin mouse 
polyclonal antibody (AT819, Beyotime) was used. The secondary antibodies utilized were horseradish peroxidaseconjugated goat anti-mouse (A0216, Beyotime) and goat anti-rabbit IgG (A0208, Beyotime).

\section{Immunofluorescence}

For immunofluorescence staining, $2 \times 10^{5}$ cells were grown in a 24-well plate and fixed with $4 \%$ paraformaldehyde at room temperature for $20 \mathrm{~min}$. After the cells were permeabilized with $0.3 \%$ Triton X-100 for $10 \mathrm{~min}$ and blocked with $5 \%$ goat serum for $30 \mathrm{~min}$ in a $37^{\circ} \mathrm{C}$ incubator, primary antibody was added to the cells and incubated overnight at $4^{\circ} \mathrm{C}$. The following day, the cells were incubated with the appropriate secondary antibodies at $37^{\circ} \mathrm{C}$ for $40 \mathrm{~min}$, and 4,6-diamidino-2phenylindol (DAPI) was added to stain the nuclei. To detect CHERP, an antibody was purchased from Abcam and used at a dilution of 1:200. For Ki67 (CST, 9449) immunofluorescence staining, we used a mouse monoclonal antibody at a dilution of 1:800. Antibodies conjugated to either Alexa Fluor 488 (Invitrogen, A21206) or Alexa Fluor $594(\mathrm{H}+\mathrm{L})$ (Invitrogen, A21203) were used at a dilution of 1:2000.

\section{RNA purification and RT-PCR}

Total RNA was purified using TRIzol reagent (Takara) according to the manufacturer's instructions, and $2 \mu \mathrm{g}$ of RNA was reverse transcribed (RT) to obtain cDNA. qRT-PCR was then performed using SYBR $\mathbb{R}$ Green PCR Master mix (TaKaRa), and the reactions were performed in triplicate using a StepOnePlus 7500 realtime PCR system (Applied Biosystems). GAPDH, an internal control, was used to normalize mRNA expression.

\section{Apoptosis analysis}

After cells were infected, they were stained with Hoechst 33258 (Beyotime), imaged with a fluorescence microscope (OLYMPUS) and scored. In preparation for the flow cytometry analysis, the infected cells were harvested and stained with propidium iodide and fluorescein isothiocyanate (FITC)-labeled annexin V for $30 \mathrm{~min}$ at room temperature. The stained cells were then counted and analyzed using a flow cytometer (BD).

\section{Soft-agar assays}

After cells were infected, 1500 cells in $1.5 \mathrm{ml}$ of $0.3 \%$ Noble agar containing supplemented media $(10 \%$ FBS + DMEM) were implanted in 6-well plates containing $1 \mathrm{ml}$ of $0.6 \%$ Noble agar and supplemented media mixture. Images were viewed using a microscope 3 weeks after the initial seeding. Colonies were stained with MTT, and the stained colonies were scanned and scored by a scanner (Lenovo).

\section{Xenograft assay}

All animal studies were performed at Southwestern University (SWU) according to the Purdue Animal Care and Use Committee. BE(2)-C cells were transfected with GFPsi and CHERPsi and expanded in DMEM/F12 supplemented with $10 \%$ FBS. Both flanks of 4-week-old NOD/SCID female mice (Beijing Laboratory Animal Research Center, China) were subcutaneously injected with $2 \times 10^{6}$ infected cells in $200 \mu \mathrm{l}$ of PBS. After seven days, tumor growth was measured using a Vernier caliper, and tumor volume was calculated using the formula $4 / 3 \pi r^{3}$. At 14 days after tumor injection, the tumors were excised and weighed.

All data were confirmed by at least three independent experiments, and the results are presented as the mean \pm S.D. P-values were calculated via Student's t-test using GraphPad Prism (version 6.0), and $\mathrm{P}<0.05$ was considered significant.

\section{ACKNOWLEDGMENTS AND FUNDING}

Our work was supported by the National Key Research and Development Program of China (2016YFC1302204), the China Postdoctoral Science Foundation (2017T100669), the National Natural Science Foundation of China (No. 81672502, 81602479) and the Chongqing University Innovation Team Building Special Fund (CXTDX201601010).

\section{CONFLICTS OF INTEREST}

The authors are not employed by any commercial companies that may have influenced the study performed here. There are no conflicts of interest.

\section{REFERENCES}

1. Modak S, Cheung NKV. Neuroblastoma: Therapeutic strategies for a clinical enigma. Cancer Treatment Reviews. 2010; 36:307-17. https://doi.org/10.1016/j.ctrv.2010.02.006.

2. Maris JM. Medical Progress: Recent Advances in Neuroblastoma. New England Journal of Medicine. 2010; 362:2202-11. https://doi.org/10.1056/Nejmra0804577.

3. Yoon KJ, Danks MK. Cell adhesion molecules as targets for therapy of neuroblastoma. Cancer Biology \& Therapy. 2009; 8:306-11. https://doi.org/10.4161/Cbt.8.4.7446.

4. Park JR, Bagatell R, London WB, Maris JM, Cohn SL, Mattay KK, Hogarty M, Comm CN. Children's Oncology Group's 2013 Blueprint for Research: Neuroblastoma. Pediatr Blood Cancer (vol 985, pg 60, 2013). Pediatric Blood \& Cancer. 2014; 61:958. https://doi.org/10.1002/pbc.24993.

5. LaPlante JM, O'Rourke F, Lu XH, Fein A, Olsen A, Feinstein MB. Cloning of human $\mathrm{Ca} 2+$ homoeostasis endoplasmic reticulum protein (CHERP): regulated expression of antisense cDNA depletes CHERP, inhibits 
intracellular $\mathrm{Ca} 2+$ mobilization and decreases cell proliferation. Biochemical Journal. 2000; 348:189-99. https://doi.org/10.1042/0264-6021:3480189.

6. Ryan T, Sharma P, Ignatchenko A, MacLennan DH, Kislinger T, Gramolini AO. Identification of Novel Ryanodine Receptor 1 (RyR1) Protein Interaction with Calcium Homeostasis Endoplasmic Reticulum Protein (CHERP). Journal of Biological Chemistry. 2011; 286:17060-8. https://doi.org/10.1074/jbc.M110.197186.

7. O'Rourke FA, LaPlante JM, Feinstein MB. Antisensemediated loss of calcium homoeostasis endoplasmic reticulum protein (CHERP; ERPROT213-21) impairs Ca2+ mobilization, nuclear factor of activated T-cells (NFAT) activation and cell proliferation in Jurkat T-lymphocytes. Biochemical Journal. 2003; 373:133-43. https://doi. org/10.1042/Bj20030013.

8. Will CL, Urlaub H, Achsel T, Gentzel M, Wilm M, Luhrmann R. Characterization of novel SF3b and 17S U2 snRNP proteins, including a human Prp5p homologue and an SF3b DEAD-box protein. Embo Journal. 2002; 21:497888. https://doi.org/10.1093/Emboj/Cdf480.

9. Saitoh N, Spahr CS, Patterson SD, Bubulya P, Neuwald AF, Spector DL. Proteomic analysis of interchromatin granule clusters. Molecular Biology of the Cell. 2004; 15:3876-90. https://doi.org/10.1091/mbc.E04-03-0253.

10. Lin-Moshier Y, Sebastian PJ, Higgins L, Sampson ND, Hewitt JE, Marchant JS. Re-evaluation of the Role of Calcium Homeostasis Endoplasmic Reticulum Protein (CHERP) in Cellular Calcium Signaling. Journal of Biological Chemistry. 2013; 288:355-67. https://doi.org/10.1074/jbc.M112.405761.

11. Sasaki-Osugi $\mathrm{K}$, Imoto $\mathrm{C}$, Takahara $\mathrm{T}$, Shibata $\mathrm{H}$, Maki M. Nuclear ALG-2 Protein Interacts with Ca2+ Homeostasis Endoplasmic Reticulum Protein (CHERP) $\mathrm{Ca} 2+$-dependently and Participates in Regulation of Alternative Splicing of Inositol Trisphosphate Receptor Type 1 (IP(3)R1) Pre-mRNA. Journal of Biological Chemistry. 2013; 288:33361-75. https://doi.org/10.1074/ jbc.M113.497479.

12. Adams JM, Cory S. The Bcl-2 apoptotic switch in cancer development and therapy. Oncogene. 2007; 26:1324-37. https://doi.org/10.1038/sj.onc. 1210220.

13. Ashkenazi A. Targeting the extrinsic apoptosis pathway in cancer. Cytokine \& Growth Factor Reviews. 2008; 19:32531. https://doi.org/10.1016/j.cytogfr.2008.04.001.

14. Cory S, Adams JM. The BCL2 family: Regulators of the cellular life-or-death switch. Nature Reviews Cancer. 2002; 2:647-56. https://doi.org/10.1038/nrc883.

15. Suzuki M, Youle RJ, Tjandra N. Structure of Bax: Coregulation of dimer formation and intracellular localization. Cell. 2000; 103:645-54. https://doi. org/10.1016/S0092-8674(00)00167-7.

16. Wang S. The promise of cancer therapeutics targeting the TNF-related apoptosis-inducing ligand and TRAIL receptor pathway. Oncogene. 2008; 27:6207-15. https://doi. org/10.1038/onc.2008.298.
17. Cui HJ, Li T, Ding HF. Linking of N-Myc to death receptor machinery in neuroblastoma cells. Journal of Biological Chemistry. 2005; 280:9474-81. https://doi.org/10.1074/jbc. M410450200.

18. Sheard MA, Asgharzadeh S, Liu Y, Lin TY, Wu HW, Ji LY, Groshen S, Lee DA, Seeger RC. Membrane-bound TRAIL Supplements Natural Killer Cell Cytotoxicity Against Neuroblastoma Cells. Journal of Immunotherapy. 2013; 36:319-29.

19. Abhari BA, Cristofanon S, Kappler R, von Schweinitz D, Humphreys R, Fulda S. RIP1 is required for IAP inhibitormediated sensitization for TRAIL-induced apoptosis via a RIP1/FADD/caspase-8 cell death complex. Oncogene. 2013; 32:3263-73. https://doi.org/10.1038/onc.2012.337.

20. Gneo L, Ruggeri P, Cappabianca L, Farina AR, Di Ianni N, Mackay AR. TRAIL induces pro-apoptotic crosstalk between the TRAIL-receptor signaling pathway and TrkAIII in SH-SY5Y cells, unveiling a potential therapeutic "Achilles heel" for the TrkAIII oncoprotein in neuroblastoma. Oncotarget. 2016; 7:80820-41. https://doi. org/10.18632/oncotarget.13098.

21. Ashkenazi A, Dixit VM. Death receptors: Signaling and modulation. Science. 1998; 281:1305-8. https://doi. org/10.1126/science.281.5381.1305.

22. Bodmer JL, Holler N, Reynard S, Vinciguerra P, Schneider $\mathrm{P}$, Juo P, Blenis J, Tschopp J. TRAIL receptor-2 signals apoptosis through FADD and caspase-8. Nature Cell Biology. 2000; 2:241-3.

23. Kischkel FC, Lawrence DA, Chuntharapai A, Schow P, Kim KJ, Ashkenazi A. Apo2L/TRAIL-dependent recruitment of endogenous FADD and caspase- 8 to death receptors 4 and 5. Journal of Investigative Dermatology. 2000; 115:1171.

24. Chen S, Liu X, Yue P, Schonthal AH, Khuri FR, Sun SY. CCAAT/enhancer binding protein homologous proteindependent death receptor 5 induction and ubiquitin/ proteasome-mediated cellular FLICE-inhibitory protein down-regulation contribute to enhancement of tumor necrosis factor-related apoptosis-inducing ligand-induced apoptosis by dimethyl-celecoxib in human non smallcell lung cancer cells. Mol Pharmacol. 2007; 72:1269-79. https://doi.org/10.1124/mol.107.037465.

25. Hetz C. The unfolded protein response: controlling cell fate decisions under ER stress and beyond. Nat Rev Mol Cell Biol. 2012; 13:89-102. https://doi.org/10.1038/nrm3270.

26. Yu XS, Du J, Fan YJ, Liu FJ, Cao LL, Liang N, Xu DG, Zhang JD. Activation of endoplasmic reticulum stress promotes autophagy and apoptosis and reverses chemoresistance of human small cell lung cancer cells by inhibiting the PI3K/AKT/mTOR signaling pathway. Oncotarget. 2016; 7:76827-39. https://doi.org/10.18632/ oncotarget.12718.

27. Pang J, Fuller ND, Hu N, Barton LA, Henion JM, Guo R, Chen Y, Ren J. Alcohol Dehydrogenase Protects against Endoplasmic Reticulum Stress-Induced Myocardial Contractile Dysfunction via Attenuation of Oxidative Stress 
and Autophagy: Role of PTEN-Akt-mTOR Signaling. PLoS One. 2016; 11:e0147322. https://doi.org/10.1371/journal. pone. 0147322 .

28. Chen XL, Fu JP, Shi J, Wan P, Cao H, Tang ZM. CXC195 induces apoptosis and endoplastic reticulum stress in human hepatocellular carcinoma cells by inhibiting the PI3K/Akt/ mTOR signaling pathway. Mol Med Rep. 2015; 12:822936. https://doi.org/10.3892/mmr.2015.4479.

29. Proud CG. Signalling to translation: how signal transduction pathways control the protein synthetic machinery. Biochemical Journal. 2007; 403:217-34. https://doi. org/10.1042/Bj20070024.

30. Shaw RJ, Cantley LC. Ras, PI(3)K and mTOR signalling controls tumour cell growth. Nature. 2006; 441:424-30. https://doi.org/10.1038/nature04869.

31. Wullschleger S, Loewith R, Hall MN. TOR signaling in growth and metabolism. Cell. 2006; 127:5-19. https://doi. org/10.1016/j.cell.2006.01.016.

32. Ma XJM, Blenis J. Molecular mechanisms of mTORmediated translational control. Nature Reviews Molecular Cell Biology. 2009; 10:307-18. https://doi.org/10.1038/ nrm2672.

33. Duvel K, Yecies JL, Menon S, Raman P, Lipovsky AI, Souza AL, Triantafellow E, Ma QC, Gorski R, Cleaver S, Heiden MGV, MacKeigan JP, Finan PM, et al. Activation of a Metabolic Gene Regulatory Network Downstream of mTOR Complex 1. Molecular Cell. 2010; 39:171-83. https://doi.org/10.1016/j.molcel.2010.06.022.

34. Hopkins-Donaldson S, Bodmer JL, Bourloud KB, Brognara CB, Tschopp J, Gross N. Loss of caspase-8 expression in highly malignant human neuroblastoma cells correlates with resistance to tumor necrosis factor-related apoptosis-inducing ligand-induced apoptosis. Cancer Research. 2000; 60:4315-9.

35. Yamaguchi H, Wang HG. CHOP is involved in endoplasmic reticulum stress-induced apoptosis by enhancing DR5 expression in human carcinoma cells. Journal of Biological Chemistry. 2004; 279:45495-502. https://doi.org/10.1074/ jbc.M406933200.

36. Axten JM, Medina JR, Feng Y, Shu A, Romeril SP, Grant SW, Li WH, Heerding DA, Minthorn E, Mencken T, Atkins C, Liu Q, Rabindran S, et al. Discovery of 7-methyl-5-(1-\{[3-(trifluoromethyl)phenyl] acetyl \}-2,3-dihydro-1H-indol-5-yl)-7H-p yrrolo[2,3-d] pyrimidin-4-amine (GSK2606414), a potent and selective first-in-class inhibitor of protein kinase R (PKR)-like endoplasmic reticulum kinase (PERK). J Med Chem. 2012; 55:7193-207. https://doi.org/10.1021/jm300713s.

37. Yan F, Cao S, Li J, Dixon B, Yu X, Chen J, Gu C, Lin W, Chen G. Pharmacological Inhibition of PERK Attenuates Early Brain Injury After Subarachnoid Hemorrhage in Rats Through the Activation of Akt. Mol Neurobiol. 2017; 54:1808-17. https://doi.org/10.1007/s12035-016-9790-9.

38. Polak P, Hall MN. mTOR and the control of whole body metabolism. Current Opinion in Cell Biology. 2009; 21:209-18. https://doi.org/10.1016/j.ceb.2009.01.024.

39. Wullschleger $\mathrm{S}$, Loewith R, Hall MN. TOR signaling in growth and metabolism. Cell. 2006; 124:471-84. https:// doi.org/10.1016/j.cell.2006.01.016.

40. Qin L, Wang Z, Tao L, Wang Y. ER stress negatively regulates AKT/TSC/mTOR pathway to enhance autophagy. Autophagy. 2010; 6:239-47.

41. Kim HS, Kim TJ, Yoo YM. Melatonin combined with endoplasmic reticulum stress induces cell death via the $\mathrm{PI} 3 \mathrm{~K} / \mathrm{Akt} / \mathrm{mTOR}$ pathway in B16F10 melanoma cells. PLoS One. 2014; 9:e92627. https://doi.org/10.1371/journal. pone.0092627.

42. Akamatsu K, Shibata MA, Ito Y, Sohma Y, Azuma H, Otsuki Y. Riluzole induces apoptotic cell death in human prostate cancer cells via endoplasmic reticulum stress. Anticancer Res. 2009; 29:2195-204.

43. Lin-Moshier Y, Sebastian PJ, Higgins L, Sampson ND, Hewitt JE, Marchant JS. Re-evaluation of the role of calcium homeostasis endoplasmic reticulum protein (CHERP) in cellular calcium signaling. J Biol Chem. 2013; 288:355-67. https://doi.org/10.1074/jbc.M112.405761.

44. Ke XX, Zhang D, Zhu S, Xia Q, Xiang Z, Cui H. Inhibition of H3K9 Methyltransferase G9a Repressed Cell Proliferation and Induced Autophagy in Neuroblastoma Cells. Plos One. 2014; 9:e106962.

45. Chen QR, Song YK, Wei JS, Bilke S, Asgharzadeh S, Seeger RC, Khan J. An integrated cross-platform prognosis study on neuroblastoma patients. Genomics. 2008; 92:195203. https://doi.org/10.1016/j.ygeno.2008.05.014. 